\title{
Assessment Gamification with Fhoment Methodology: An Action Research Based Case Study
}

\author{
Miguel Ecar $^{1}$, João Pablo S. da Silva ${ }^{1}$ \\ ${ }^{1}$ LabISE - Laboratory of Intelligent Software Engineering \\ Federal University of Pampa - UNIPAMPA \\ Alegrete - RS - Brazil \\ miguel@ecarsm.com, joaosilva@unipampa.edu.br
}

\begin{abstract}
Gamification has been one of the most popular modern strategies in high education. It can be used to stimulate learning, and obtain knowledge by side effect, while playing. Students assessment is a topic that that divides opinions. At the same time there must be an evaluation strategy, there is no a specific one that may be said completely fair. Several problems may impact in the student assessment score, with no directly relation to knowledge. In order to reach this problem, we propose Free Choice to Obtain Assessment Benefit Fhoment) Methodology. Fhoment is a methodology that offers assessment benefits in exchange of currencies, obtained through assignments. We Applied Fhoment in 2 under graduation courses. Results suggest good acceptance from students, better students involvement and positive impact on assessment results.
\end{abstract}

\section{Introduction}

Gamification has been one of the most popular modern strategies in high education. Gamification in particular has been considered one of the key emergent and widely adopted teaching technologies in education [Alhammad and Moreno 2018, Johnson et al. 2016]. Gamification can be used to stimulate learning, and obtain knowledge by side effect, while playing.

Students assessment is a topic that that divides opinions. At the same time there must be an evaluation strategy, there is no a specific one that may be said completely fair. The most traditional evaluation forms include, written tests, research activities and group mini projects [Silva et al. 2019].

In order to reach this problem, we propose Free Choice to Obtain Assessment Benefit (Fhoment) Methodology. Fhoment is a methodology based on gamification that offers assessment benefits in exchange of currencies, obtained through assignments.

The Fhoment Methodology is composed of Principles, Rules and Workflow. Principles are the basic beliefs that guide Fhoment Methodology. Rules are inspired in Principles, they exist to help in the methodology conduction. We Applied Fhoment Methodology in 2 undergraduate courses.

We advocate that Fhoment Methodology helped students to study and fix knowledge through doing assignments. Moreover, we consider that extra points obtained in Fhoment help to have better assessment results. Furthermore, the students freedom to do or not assignments, and whether and what benefit to buy, helps to maintain better equality among different students characteristics. 
The rest of the paper is organized as follows: section 2 present a short background of Gamification and its application in education; in section 3 we present the related works; in section 4 we present the Fhoment Methodology; in section 5 we present the action Research Case Study; section 6 presents our conclusion and future work.

\section{Gamification}

[Zichermann and Cunningham 2011] say that gamification is a term which may have different meanings depending on the context. According to [Deterding et al. 2011] Gamification refers to the use of design game technology or practices, game elements or game characteristics in non-game context.

[Huotari and Hamari 2011] define gamification as "a process of enhancing a service with affordances for gameful experiences in order to support user's overall value creation". They highlight that this definition does not mean that the gamification process has to be successful, gamification can only attempt to support the user in creating gameful experiences [Huotari and Hamari 2011].

For other point of view gamification may be considered a design process. [Salen and Zimmerman 2004] say that gamification can be a framework where participants are systematically motivated with targets. Following the definition of [Deterding et al. 2011], they highlight that game elements are difficult to specify.

In Education, gamification has been used as a stimulation factor to instigate students to learn. Gamification in particular has been considered one of the key emergent and widely adopted teaching technologies in education [Alhammad and Moreno 2018, Johnson et al. 2016]. According to [de Almeida Souza et al. 2017], recent technologies have provided new opportunities for using games and their elements to enhance learning and student engagement.

\section{Related Work}

In this section we present some related works, that also propose methodologies or approaches to add gamification in Software Engineering or Computer Science education.

[Silva et al. 2019] propose a methodology of gamification strategies application for student evaluation. The methodology was used two high school classes, in a total of 71 students, using a developed gamification system. The authors highlight as result, transparency of results, speed of feedback and student autonomy. They also mention a better students engagements and visualization. Moreover, different from traditional students evaluation, the proposed methodology could identify students who needed specific approaches to reach learning goals.

[Pessoa et al. 2019] present a structural gamification platform called CodePlay, which has elements and mechanics typical of Role Play Game (RPG) games. The platform was integrated into an online judge and used by 9 introductory programming classes. Since it is based on RPG games, each student on this platform assumes the role of a character that will be used to visit places, interact with other characters, fight against enemies, etc. After experimentation, the authors mention that the platform helped to improved scores of students who already would get approval. They also advocate that their approach helped to increase students engagement. Moreover, they said that students had a good acceptation of the used gamification approach. 
[Zanin et al. 2018] propose a tool to support the performance of extra class activities called StudyPlay. It is a tool that, through rewards, stimulates the student to carry out the activities and, in addition, allows the activities to be performed on any mobile device, facilitating access. At the moment of the study publication, the tool were under testing phase, but preliminary results indicates a good students motivation and knowledge generator, through the use of StudyPlay.

Considering the mentioned related studies, our proposal differs from them, once it is a methodology to help students in getting extra benefits in assessments. This benefits are obtained through assignments that are directly related to assessment content.

\section{Fhoment Methodology}

In this work we propose the Free Choice to Obtain Assessment Benefit (Fhoment) Methodology. The Fhoment Methodology is based on gamification, and it is composed of Principles, Rules and Workflow.

Principles are the basic beliefs that guide Fhoment Methodology. During the conduction of the methodology there should always look at the principles, in order to promote the best of the methodology. They are:

1. Freedom - Students must be free of choice.

2. Currency Uniqueness - There must be a unique Currency or "Coin" as prize.

Rules are presented in Table 1. Rules are inspired in Principles, they exist to help in the methodology conduction. Rules should be respected and used during the whole workflow, to help in creation and decision making.

Table 1. Fhoment Rules

\begin{tabular}{ll}
\hline $\mathbf{N}^{\mathbf{0}}$ & Rule \\
\hline R01 & The student must be free to take assignment. \\
R02 & The student must be free to choose the benefit based on earned currency. \\
R03 & The currency must be the one benefit received over the course. \\
R04 & The benefit must be proportional to its cost. \\
R05 & The assignment prize must be proportional to its difficulty degree. \\
R06 & There must be transparency to the currency holders ranking. \\
R07 & Benefits must be related to the assessment (preferably) or to the final score calculation. \\
\hline
\end{tabular}

The Figure 1 shows the workflow to be followed when using Fhoment First, a currency must be defined, it is recommended to create a currency and give a name to it.

Next, one should create the initial list of benefits and its respective cost, based in the currency. This list can be updated during the process, adding or removing a benefit. It is highly recommended that the benefits should be related to assessments, in other words, the benefit should be directly a related to help increasing the student performance in assessments. Other important recommendation is that students to participate of this list creation, suggesting benefits and how much it should cost. However, the final decision about this variable is always from the Professor.

The third task is to create assignments and inform how much is the assignment reward. Based on this, the student can decide whether to do the assignment or not. Assignments should be created during the course as many as the professor decided it is 


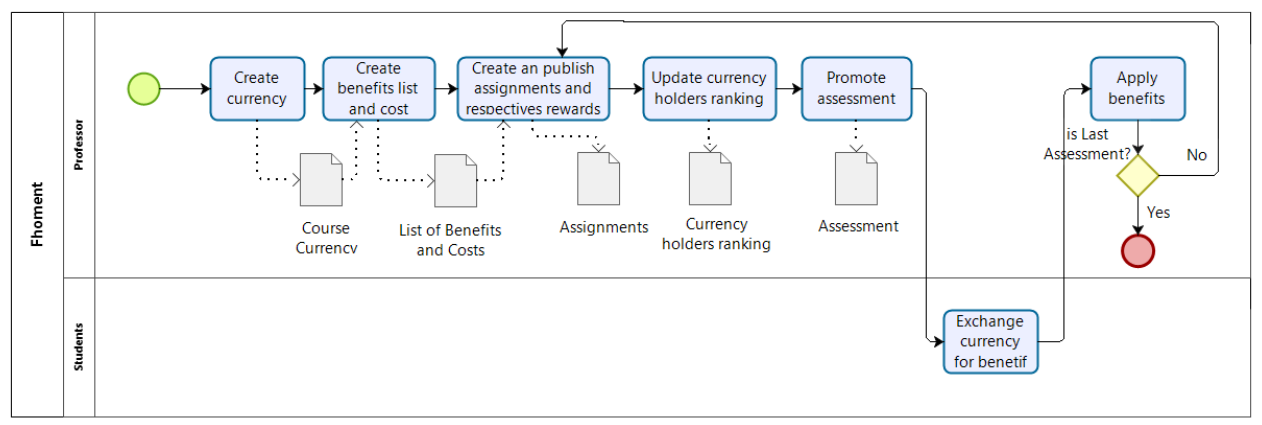

Figure 1. Fhoment Workflow

needed. Always remembering that the final assignments goal is to help students to learn and fix the given knowledge.

Following, as soon as the assignments deadline is reached, it should be revised and the currency holders ranking should be updated and published. It is a important part of the gamification process to have transparency in the ranking once it instigate to play the game.

Next step is to promote an assessment. That is the moment when students chose what benefit to exchange or to buy. As mentioned in Fhoment principles, students should be free to choose whether and what benefit to buy.

Finally, the assessment is corrected and the bought benefit is applied. If there are more assessment during the course the currency holders ranking should be updated and more assignments provided, until there is no more assessments.

An important point to highlight, is that Fhoment states rules and workflow but, when applying the methodology the Professor should be free to create and personalize it. In different situations, adjusts should be done to best fit in the context.

\section{Case Study}

This case study was conducted based on the Action Research Methodology. Action Research is a research strategy to perform qualitative applied scientific research, of a participatory nature [Filippo et al. 2018].

In our case study, we used Goal Question Metric (GQM) methodology [Van Solingen et al. 2002] to guide our Action Research process. First of all we defined GQM goal as following:

$$
\begin{aligned}
\text { Analyze } & \text { the use of Fhoment Methodology } \\
\text { for the purpose of } & \text { understand how it helps students to absorb knowledge } \\
\text { with respect to } & \text { improve assessments result scores } \\
\text { from the point view of } & \text { researchers } \\
\text { in the context of } & \text { undergraduate students. }
\end{aligned}
$$

Then, we defined three questions. These questions are important to define the importance of Fhoment Methodology. They are:

- RQ01 - How Fhoment helps in learning? 
- RQ02 - How Fhoment helps to obtain better assessment result scores?

- RQ03 - There is coherence among assignments rewards, difficult degree and benefits cost?

Finally, metrics are collected by analyzing data from the methodology running. We collected and analyzed data from assignments resolutions, how benefits were bought during the course, the relation of bought benefits with assessments scores, and a survey at the end of all iterations.

\subsection{Action Research}

We executed the Fhoment Methodology in two courses of Computer Science Bachelors simultaneously. In both courses we created and applied the same benefit structure. These benefits were directly related to test assessments.

The course of Object Oriented Programming, ministered to fourth semester, was composed of 40 students. In this course we applied 4 assessment all of them were tests. We will call it Execution 1.

The Software Engineering II course, ministered to sixth semester, was composed of 14 students. In this course we applied also 5 assessments, 3 tests and 2 presentations. For this course, we only used benefits for tests. This was done in order to have the same criteria for both executions. We will call it Execution 2.

Considering the iterative Action Research life cycle, we performed 4 iterations for Execution 1 and 3 iterations for Execution 2.

As the stated by Action Research Methodology [Filippo et al. 2018], the execution was divided in three moments, Planning, Action and Reflection. Next subsections present the summary of all iterations for each moment.

\subsubsection{Planning}

In the first planning iteration, we created and named the currency. We called it Coin to Obtain Assessment Benefits (Cota), This name and acronym were chosen in order to simplify when talking about it, it should sound like a familiar word.

The Table 2 shows the benefits list and their costs. This table was provided in all test assessment, so the student could chose whether and what benefit to buy. The only benefit not directly related to assessments is the number 001. This benefit is indirectly related to assessment, once there is an institutional rule of $75 \%$ minimum presence to pass in the course.

For both executions, we planned, of course, to provide the total number of Cotas to buy the most valuable item, if they save.

The decision of to do assignments were completely up to students. They could decide whether to do a assignment or not. The only reward was Cotas, and of course, the final goal was always to help to fix the content.

In each iteration of planning we collected feedback from students in order to have a better experience, they could suggest types of assignments, new rewards and benefits, etc. 
IX Congresso Brasileiro de Informática na Educação (CBIE 2020)

Anais do XXXI Simpósio Brasileiro de Informática na Educação (SBIE 2020)

Table 2. Fhoment benefits and cost

\begin{tabular}{lllr}
\hline $\mathbf{N}^{\mathbf{0}}$ & Benefit & Description & Cotas \\
\hline 001 & Presence & $\begin{array}{l}\text { With this item you can replace an absence by a } \\
\text { presence. }\end{array}$ & 30 \\
002 & 1 Extra point in Final Result & $\begin{array}{l}\text { With this item you can add an extra point in the } \\
\text { final score calculation }\end{array}$ & 250 \\
003 & 1 Extra point in the Assessment & $\begin{array}{l}\text { With this item you can add an extra point in this } \\
\text { assessment }\end{array}$ & 60 \\
004 & Test as top 12 & $\begin{array}{l}\text { With this item the sum of all test questions are 12. } \\
\text { As the normal test has value of 10. It means that } \\
\text { the score is increased by using a simple rule of } \\
\text { three. }\end{array}$ & 50 \\
005 & Buy a Question & $\begin{array}{l}\text { With this item you can buy a question in this as- } \\
\text { sessment. In other words, the chosen question } \\
\text { does not need to be done to get its value. }\end{array}$ & 200 \\
006 & Replace Question Values & $\begin{array}{l}\text { With this item you can chose 2 questions and re- } \\
\text { place the value of each other. Remember to inform } \\
\text { what question to exchange values. }\end{array}$ & 75 \\
\hline
\end{tabular}

For example, the benefit 006, was suggest by a student and added to the list during the second iteration. This benefit was particularly challenging due to after that, test question values should be well balanced, in order to avoid unfair replacements, such as, replace a difficult question with value of 4 to other easier with value of 0.5 .

\subsubsection{Action}

In each action iteration we created balanced the number of provided Cotas and the specific assignments to provide for current cycle.

Execution 1. We provided 350 Cotas, distributed in 16 assignments, with different reward values and difficult degree levels.

In the first iteration, we provided 75 Cotas. Only 2 students could accumulate enough to buy a benefit in the first assessment. In the second iteration, we provided plus 80 Cotas totalizing 155 Cotas. In this one, 5 students bought benefits. In third iteration, we provided plus 155 Cotas totalizing 310 Cotas. Now, 14 students used Cotas to buy benefits. In the fourth and last iteration, we provided plus 40 Cotas totalizing 350 Cotas. This this last one, 5 students used Cotas to buy benefits.

Execution 2. We provided 260 Cotas, distributed in 9 assignments, also with different reward values.

In the first iteration, we provided 90 Cotas 2 students used Cotas to buy benefits in this iteration. In the second iteration, we provided plus 130 Cotas totalizing 220 Cotas. In this one, 9 students bought benefits. In the third and last iteration, we provided plus 40 Cotas totalizing 260 Cotas. For this last one, only one student used Cotas to buy benefits.

In Execution 1 we provided more Cotas once it has 4 test assessments, while in Execution 2 there are only 3. In both executions we planned a wide range of assignments, such as, quizzes practical exercises, content summaries, mini projects, etc. 
IX Congresso Brasileiro de Informática na Educação (CBIE 2020)

Anais do XXXI Simpósio Brasileiro de Informática na Educação (SBIE 2020)

\subsubsection{Reflection}

In the reflection moment of each iteration, we analyzed how the Methodology conduction was running.

Execution 1. From the total of 40 students in this course, 18 students used Cotas to buy benefits in at least 1 assessment. From the students who did not used Cotas in any assessment, the majority did not do any assignment during the course, thus, they did not get any Cota.

All the 18 students who did assignments and used Cotas could manage to pass in the course. From this total, 8 students, probably, could not pass in the course without buy benefits, due to their final score was so close to the minimum. Other 5 students could also manage to pass in the curse without do assignments and use Cotas. We also highlight other 2 students who would manage to pass if they had done assignments and used Cotas, due to their final score was close, but, under the minimum.

Execution 2. From the total of 14 students, 9 of them used Cotas to buy benefits in at least 1 assessment. These 9 students could manage to pass in the course plus other 3 students whom did not used Cotas. From the students who used Cotas, 3 of them probably would not manage to pass in the course without use Cotas.

At last, we ran a questionnaire after all iterations to get a feedback from students. The main goal of the questionnaire is to obtain the students perceptions about the methodology, from their point of view. We used content analysis in order to analyze the collected information. The questionnaire answers are presented following, join both executions. We got a total of 39 answers, as stated in the Fhoment Methodology, student were free to answer or not. Thus, the result were analyzed considering overall answers.

The questionnaire was composed of 4 questions, presented following:

- Q01 - Doing assignments in exchange of Cotas helped you to learn the course content?

- Q02 - This Methodology saved your course score?

- Q03 - Do you believe that benefits were coherent with its respective costs?

- Q04 - If possible, would you like to use this Methodology again?

Table 3 show the content analysis for the question Q01. Following the content analysis methodology, the answers were divided in 3 groups, "Yes", "No" and "Didn't do" answers. Considering the "Yes" answers, majority of the students consider the methodology helped them to study and fix the content. For "No" answers, some students did not see helpfulness in this methodology. The last group is about the ones who did not do assignments, consequently did not get Cotas. They mention that doing assignments were not necessary.

Table 4 show the content analysis for the question Q02. The answers were divided in 2 groups, "Yes" and "No" answers. The "Yes" answers show some students perceptions that the methodology could help to guarantee approval in the course. The "No" answers show that students majority consider that it helps but it is not the reason to get approval.

Table 5 show the content analysis for the question Q03. The answers were also divided in 2 groups, "Yes" and "No" answers. The "Yes" answers were the biggest major- 
Table 3. Q01 - Doing assignments in exchange of Cotas helped you to learn the course content?

\begin{tabular}{lll}
\hline Group & Class & Percent \\
\hline Yes & $\begin{array}{l}\text { "helped a lot", "good stimulation", "mainly the ones to } \\
\text { summary a paper", "specially in the second assessment" }\end{array}$ & $74.35 \%$ \\
No & "it does not help" & $7.69 \%$ \\
$\begin{array}{l}\text { Didn't } \\
\text { do }\end{array}$ & "I did not get any", "I did not think necessary" & $17.94 \%$ \\
\hline
\end{tabular}

Table 4. Q02 - This Methodology saved your course score?

\begin{tabular}{lll}
\hline Group & Class & Percent \\
\hline Yes & "maybe", "I hope so, probably", "with absences" & $28.21 \%$ \\
No & "But helped", "but it is a interesting stimulus", "but it is & $71.79 \%$ \\
& a great idea" & \\
\hline
\end{tabular}

ity. Students mention that costs were fair. They also say that even fair, it could be better balanced. Students who answered "No" answers, mention that benefits were expensive.

\section{Table 5. Q03 - Do you believe that benefits were coherent with its respective costs?}

\begin{tabular}{lll}
\hline Group & Class & Percent \\
\hline Yes & "but it could be better balanced", "costs were fair” & $84.62 \%$ \\
No & "All benefits were expensive” & $15.38 \%$ \\
\hline
\end{tabular}

Table 6 show the content analysis for the question Q04. The answers were divided in 2 groups, "Yes" and "No" answers. Considering the "Yes" answers, the large majority of students consider that surely this methodology could be applied again. They also highlight that it is helpful and better than other attempts to help at the end of the semester, such as, a single extra point. Other interesting point is that this assignments are a great alternative to help fixing the course content, and Cotas are a good stimulus to do assignments. The "No" answers were few and just mention that it not an interesting methodology.

Table 6. Q04 - If possible, would you like to use this Methodology again?

\begin{tabular}{lll}
\hline Group & Class & Percent \\
\hline Yes & $\begin{array}{l}\text { "for sure", "it is helpful", "it is better than just a single } \\
\text { extra point at the end of the semester", "it is a great alter- }\end{array}$ & $94.87 \%$ \\
& $\begin{array}{l}\text { native to fix content" } \\
\text { No }\end{array} \quad$ "do not think it interesting" & $5.13 \%$ \\
\hline
\end{tabular}

\subsection{Discussion}

Returning to our research questions, we present our answers to them based on the results from case study. Following, we present the answers for our research questions. 
RQ01 - How Fhoment helps in learning? Based on the data collected during the case study, we say that Fhoment might be a helpful instrument to support learning. Considering the answers from questionnaire, some students said that most assignments helped them to study and learn the assessment contents. The idea of having a prize and this prize be used to obtain benefits in assessments, can stimulate students to do the assignments and by consequence, to learn and to fix the assessment contents.

RQ02 - How Fhoment helps to obtain better assessment result scores? As we also mentioned previously, a significant number of students would not be approved in the course but, due to benefits bought with Cotas they could obtain approval. We advocate that it does not mean that they were approved without learning, but in opposite, test assessments are not always fair, thus, this mechanism can help students to get extra points, once they needed to do assignments related to the assessment content to get this points.

RQ03 - There is coherence among assignments rewards, difficult degree and benefits cost? At last, we asked about the coherence among rewards, difficult degree and benefits cost. This question is important once, if there were not coherence, it could be a discouraging factor to keep using Fhoment Methodology. As we could analyze in case study, students said that there were coherence among these elements. Furthermore, the large majority of students would like to keep this methodology in the future.

\section{Conclusion and Future Work}

Students assessment is a topic that that divides opinions. At the same time there must be an evaluation strategy, there is no a specific one that may be said completely fair. Gamification can be used to stimulate learning, and obtain knowledge by side effect, while playing.

We propose Free Choice to Obtain Assessment Benefit (Fhoment), that is a methodology based on gamification that offers assessment benefits in exchange of currencies, obtained through assignments. We performed a case study based on action research to evaluate out methodology.

We advocate that Fhoment Methodology helped students to study and fix knowledge through doing assignments. Moreover, we consider that extra points obtained in Fhoment help to have better assessment results.

Considering our case study research questions, we say that Fhoment might be a helpful instrument to support learning. Students said that most assignments helped them to study and learn the assessment contents. The idea of having a prize and this prize be used to obtain benefits in assessments, can stimulate students to do the assignments and as consequence, to learn and to fix the assessment contents. Students also said that there were coherence among these elements. It is important, due to, if there were not coherence, it could be a discouraging factor to keep using Fhoment Methodology. Furthermore, the large majority of students would like to keep this methodology in the future.

Furthermore, the students freedom to do or not assignments, and whether and what benefit to buy, helps to maintain better equality among different students characteristics.

As Future work, we intend to apply this methodology in other courses with different maturity stage students. We also consider to develop a software tool to help conducting 
IX Congresso Brasileiro de Informática na Educação (CBIE 2020)

Anais do XXXI Simpósio Brasileiro de Informática na Educação (SBIE 2020)

and automate Fhoment Methodology.

\section{References}

Alhammad, M. M. and Moreno, A. M. (2018). Gamification in software engineering education: A systematic mapping. Journal of Systems and Software, 141:131-150.

de Almeida Souza, M. R., Constantino, K. F., Veado, L. F., and Figueiredo, E. M. L. (2017). Gamification in software engineering education: An empirical study. In 2017 IEEE 30th Conference on Software Engineering Education and Training (CSEE\&T), pages 276-284. IEEE.

Deterding, S., Dixon, D., Khaled, R., and Nacke, L. (2011). From game design elements to gamefulness: defining gamification. In Proceedings of the 15th international academic MindTrek conference: Envisioning future media environments, pages 9-15. ACM.

Filippo, D., Roque, G., and Pedrosa, S. (2018). Pesquisa-ação: possibilidades para a informática educativa. Metodologia de Pesquisa Científica em Informática na Educação: Abordagem qualitativa de Pesquisa, 3.

Huotari, K. and Hamari, J. (2011). Gamification" from the perspective of service marketing. In Proc. CHI 2011 Workshop Gamification.

Johnson, L., Becker, S. A., Cummins, M., Estrada, V., Freeman, A., and Hall, C. (2016). NMC horizon report: 2016 higher education edition. The New Media Consortium.

Pessoa, M., Fernandes, D., de Carvalho, L. S. G., Oliveira, E., Nakamura, W., and Conte, T. (2019). Codeplay: Uma plataforma de gamificação baseada em jogos de rpg multiplayer. In Brazilian Symposium on Computers in Education (Simpósio Brasileiro de Informática na Educação-SBIE), volume 30, page 843.

Salen, K. and Zimmerman, E. (2004). Rules of play: Game design fundamentals. MIT press.

Silva, J. C., Rodriguez, C., and da Rocha, R. V. (2019). Uma metodologia para aplicação de estratégias de gamificação na avaliação da aprendizagem de alunos. In Brazilian Symposium on Computers in Education (Simpósio Brasileiro de Informática na Educação-SBIE), volume 30, page 1002.

Van Solingen, R., Basili, V., Caldiera, G., and Rombach, H. D. (2002). Goal question metric (gqm) approach. Encyclopedia of software engineering.

Zanin, A., Sparremberger, A., Becker, T., and Barbosa, J. (2018). Studyplay: Um modelo gamificado para incentivo a realização de atividades extraclasse. In Brazilian Symposium on Computers in Education (Simpósio Brasileiro de Informática na EducaçãoSBIE), volume 29, page 1683 .

Zichermann, G. and Cunningham, C. (2011). Gamification by design: Implementing game mechanics in web and mobile apps. " O’Reilly Media, Inc.". 